\title{
Editorial
}

\section{Formative Pathways | Changing Systems of Design - From Heuristics to Applications, Pedagogies, and Processes}

"Architecture is not about the conditions of design, but about the design of conditions."

Bernhard Tschumi, (Tschumi, 1994)

This special issue of International Journal of Architecture Computing (IJAC) is entitled Formative Pathways and explores the changing face of the profession and the academy as a means to capture the influence of computational methods on architecture and design. The selected papers describe the integration of those approaches into pedagogies and practices and demonstrate their transformative and disruptive effect on the norms and traditions of design, discourse, design education, and practices, and how this knowledge exchange continues to shape today's theory and practice of architecture. The ideas discussed by the authors are characterized by procedures that expand beyond the techniques of crafting things to include broader design knowledge of heuristics, applications, pedagogies, and their often simultaneous influence on design processes and practices in the academic and professional realms.

The increasing relevance of design computation is demonstrated by the societal impact that we are witnessing in individually customized innovative products and in performance-optimized buildings. With the widespread adoption of parametric modeling (including Building Information Modeling), performative modeling, digital fabrication, robotics and other computational methods, discourses of practices and education are shifting beyond a focus on tools and products and expanding to include the processes and pedagogy of design. However, as noted in the Formative Pathways call for participation, the scholarship of the processes, pedagogies, and practices lags behind the scholarship of tools, techniques, and products. This is to be expected; as understanding of an innovation is cultivated and disseminated, the first step is likely to be an examination of the artifacts rather than the theory or consequences.

Computational invention and innovation are not so much a disciplinespecific means to an end, but have become a part of an integrated and productive feedback loop that constantly resituates design as a creative act. While it may already be generally accepted that the products of design can be understood from multiple vantage points ranging from object-oriented ontology (Harman, 20I0) to systems thinking, we may also need to understand the tools, design organizations, and processes of design as a 
larger system of design that is necessary for the production of products and spaces. Because of this new system of design, processes of practice are changing, morphing, and mutating. As a consequence, transformative pedagogies are emerging. The philosophical underpinnings of design education are shifting a fortiori, as a logical result of research-driven faculties that are constantly questioning the a priori conditions of the tools while searching for critical gaps in their usage. The selected papers suggest that this process of discovery is not as a means to an end, but rather is an "emergent possibility" where "the priority of the representation is replaced by the priority of performance" - as articulated by Juhani Pallasmaa (Pallasmaa, 1993) - could narrow the seams between meaning, making, analysis, and imagination. The selected texts also explore how the recursion of abductive reasoning processes synergistically informs the act of design - a creative enterprise aligned with an enhanced learning context capable of fostering integrative approaches. The papers further position collaborative design processes vis-à-vis decision-making optimization and by rethinking pedagogy.

\section{From Heuristics}

In their essay, "Multi-Objective Heuristic Computation Applied to Architectural and Structural Design:A Review," Leonardo Moreno De Luca and Oscar Javier Begambre Carrillo situate the field of multi-objective optimization through a comprehensive literature review with detailed and exhaustive references of various types of evolutionary and heuristic methods related to the work of researchers in this domain. De Luca and Carrillo's essay could serve as an excellent compendium that cites the most relevant work done by others in this field. While the authors do not directly experiment with heuristic methods, their paper catalogues previously published research, clearly presenting the state-of-the-art in multi-objective evolutionary and heuristic algorithmic methods. The authors present a wellstructured examination of basic algorithmic concepts and further elucidate the topic through specific references to topological applications in architecture, such as Finite Element Analysis (FEA)-based optimizations, as a viable decision-making methodology for approaching complexity. Within this context, the tool becomes a heuristic mechanism for informing a holistic design solution. In this sense, the heuristic models serve as design tools that are useful not only in the conceptual design phases of a project but also in the application of computational strategies that ultimately bridge creativity and performance and lead to optimized design solutions rooted in innovation. By interrogating the relevant tools for developing optimal alternatives that assist the designer throughout the decision-making process, the authors present these evolutionary algorithms through a range of iterations or "differentiated approaches" that further define the "fitness" of a proposed solution. 


\section{To Applications}

"For every complex problem there is an answer that is clear, simple, and wrong." H.L. Mencken

In developing the Formative Pathways issue, the editors explored the interstices of a current trend that often references the work of Horst Rittel on wicked problems (Rittel and Webber, 1973) as a way to better connect the fundamental nature of architectural design problems to multi-objective optimization and challenges the foundational grounding of an architect as being a sole author. Rather, designers now operate in a realm of strategies and tactics that have moved towards a more collaborative context that reframes the designer as an interdisciplinary auteur who guides the conceptual direction of a project. In "Comparing Designer's Behavior in Responding to Unexpected Discoveries in Parametric Design Environments and Geometry Modeling Environments," Rongrong Yu, Ning Gu, and Juhyun Lee compare and contrast parametric and geometric modes of examining serendipitous discovery in the design process. This investigation examines the cognitive understanding of design processes as a shared technical platform for design creation. Through protocol analysis the authors reconstruct design-situatedness as a flexible and dynamic method of finding form given a series of possibilities. Collectively, these tools present the creation of meaningful architecture and the process of its discovery as a dynamic act that is rooted in a cross-fertilization of approaches more akin to synaptic thinking than intuition. This direction aligns with Richard Garber's 2009 ascertain that future projects will be informed in a manner that translates essential concepts, ideas, forces, and components to be input to more verifiable tools that influence the means of production, systematic optimization, and performance validation (Garber, 2009).

\section{To Pedagogies}

"Collaboration is a constellation of interconnected mindsets," (Luhan, 2013)

In his essay, "Making Ripples: Rethinking Pedagogy in the Digital Age," Murali Paranandi presents a project that informs pedagogical approaches and describes the potential intellectual significance of the graphic/studio/shop approach to project delivery by highlighting links to subsequent levels of product design. Within this context Paranandi demonstrates how the project complements, challenges, and expands upon relevant studies in the field. Paranandi presents a design-thinking research/fabrication project aimed at introducing digital fabrication methods and techniques that in turn develop an enhanced framework for integrated learning. The intended translational framework expands to include the critical relationships between the projects "Shape Grammars" (form and pattern) and "Motion Grammars" (rotation and translation) as being inter- 
related, process-derived vocabularies that focus more on the adaptive nature of the structures than on the static form-generating methodologies that the author, along with architects such as Rem Koolhaas, rejects.

Paranandi presents a digital pedagogy that enables a rethinking and retooling of teaching practices that aim specifically at developing the students' critical thinking skills to enable a formative way of accessing and evaluating complex data sets. Paranandi successfully presents the context of the design studio as an operative "big room" that weaves specialized knowledge from a variety of disciplines into an enhanced and integrative learning experience. Further, the author expresses how through both subtle and significant changes to design pedagogy, one could amplify the collaborative nature of the project's plug-and-play diagrid and its subsequent "Lighting across the Design Curriculum" to be equally as dynamic as the product itself. Drawing inspiration from David Bailey's grid-filling "World of Escher-like Tessellations," the author's link to connectivism and constructivist approaches to design pedagogy is particularly noteworthy. It frames the iterative experiments as "strategies for action" that could situate the various forms of optimizations in light of their research trajectories as either additional work examples and/or as subsequent lessons learned. As an educator and researcher, Paranandi goes another step further by describing a process that suggests that the feedback loop is actually a context for engaging a different type of "social network" that could provide further intellectual justification for this type of project. In doing so, Paranandi addresses four key areas that are particularly relevant to the academy today, most notably: research and contribution; methods and work plan; competencies, skills, and access to information; the final product; and its ultimate dissemination.

\section{To Processes}

As noted in Paranandi's essay, there is an emerging framework that starts with interdisciplinary modalities of education - workshops, peer-to-peer learning, and short courses that deepen lessons learned, enhance procedural skills, and develop competencies. By activating students' awareness of these complex "pools of knowledge," the role of failure is introduced as a means to lead the designer through a project's evolution. These collaborative exchanges link tools and techniques to the pedagogy's philosophical underpinnings - experimentation in a research-based inquiry. Daekwon Park and Martin Bechthold present education and pedagogy as a system in the same manner that a building might be considered a system. In their essay, "Designing Biologically-Inspired Smart Building Systems: Processes and Guidelines," the authors draw inspiration from natural systems to interrogate the systemic complexity, materiality, and performance of responsive systems. The authors present a mode of inquiry that involve multidisciplinary fields of study using kinematic and scalar iterations as a 
means for validating and optimizing responsive architecture. Their modular prototypes are creative deployments - a lens through which to embrace scientific modes of discovery that in turn result in Biologically-Inspired Smart Building Systems (BISBS).

\section{CONCLUSIONS}

Collectively, the papers selected for the Formative Pathways Special Issue offer a glimpse into the systemic contexts of digital design today and how problems could be addressed from a systems perspective and thus, be used as an inclusive educational model that includes design thinking (Luhan, 20I3). Collectively, the authors articulate a process-driven feedback loop for research that seamlessly moves among discovery, heuristics, and algorithms. Discovery develops from precise concepts based upon research such as design using specific algorithms; heuristics emerge as simplistic general rules of thumb to "stand on the shoulders of others" that may lead to new algorithms. Potential design schemes are informed by algorithmic possibilities that are then further informed by the process and the methods of fabrication. This evolutionary process continues to move towards an organized exploration of possibilities that create value from a designerly way of understanding the world.

These possibilities enable a multi-dimensional and convergent framework that leads to "just-in-time" decision making - a flexible means of moving knowledge forward, ultimately enabling translation into a lived experience. In this context, the classroom context is a 4-dimensional textbook that requires collaboration for problem solving. This collaborative context is rooted in innovation methods that include abductive reasoning, design thinking, systems thinking, grounded theory, facet theory, emergent theory, and integral theory. These methods in turn inform material selection, fabrication, and formation; building sustainability and product performance; force modeling and scripting; physical testing and virtual simulation. By deploying a comprehensive approach that includes as many perspectives, systems, and methodologies as possible while retaining coherency; such integrated approaches are "meta-paradigms" that draw together mutually enriching domains. The new system of design simultaneously demonstrates and questions the roles of architects and engineers and their collective influence on the design processes. Working together, these papers and projects validate emerging synergistic design processes and serve as departure points for future design processes and educational inquiry.

\section{ACKNOWLEDGEMENTS}

We would like to thank the many paper reviewers for their tireless efforts in their critique and advice for developing the research papers. We would also like to acknowledge Andy Payne a doctoral student at Harvard University, Stephen Caffey at Texas A\&M University and Michael Fox at the 
University of California-Pomona for their topical discussions in developing the introduction to the Formative Pathways Special Issue.

\section{REFERENCES}

Garber, R. (2009). "Closing the gap: information models in contemporary design practice,” Architectural Design, Vol. 79, No. 2, March/April 2009.

Harman, G. (2010). Towards Speculative Realism: Essays and Lectures, Ripley: Zero Books.

Luhan, G. and Gregory, R. (20I3). Across disciplines: triggering frame awareness in design education. In M. Bernal, P. Gomez (Eds.), XVII Congreso de la Sociedad Iberoamericana de Grafica Digital: Knowledge-based Design, pp. 619-623.

Pallasmaa, J., "From Metaphorical to Ecological," The Architectural Review, June 1993, Pp. 74-79.

Rittel, H. and Webber, M. (1973). Dilemmas in a general theory of planning. Policy Sciences 4, Pp. I55-169.

Tschumi, B. (1994). Architecture and disjunction. Cambridge, MA: MIT Press.

\section{Senior Editors}

Mark Clayton', Mahesh Daas ${ }^{2}$, Wassim Jabi ${ }^{3}$ and Gregory Luhan ${ }^{4}$

'Texas A\&M University

mark-clayton@tamu.edu

${ }^{2}$ Ball State University

mahesh@mahesh.org

${ }^{3}$ Cardiff University

jabiw@cardiff.ac.uk

${ }^{4}$ University of Kentucky

gregory.luhan@uky.edu 